\title{
Adsorption of acetaldehyde from air by activated carbon and carbon fibers
}

\author{
Soohyung Park' ${ }^{1}$, Muhammad Yaqub ${ }^{1}$, Seunghan Lee ${ }^{2}$, Wontae Lee ${ }^{1^{\dagger}}$ \\ ${ }^{1}$ Department of Environmental Engineering, Kumoh National Institute of Technology, Gumi, South Korea \\ ${ }^{2}$ Industry Academy Cooperation Foundation, Kumoh National Institute of Technology, Gumi, South Korea
}

\begin{abstract}
The adsorption of acetaldehyde from air using various activated carbon and carbon fibers was investigated in this study. These adsorbents included activated carbon $(\mathrm{AC})$, carbon fibers $(\mathrm{CFs})$, activated carbon fibers $(\mathrm{ACFs})$, and metal-coated carbon fibers $(\mathrm{MCCFs})$ supplied by different manufacturers. $A C$ was categorized as $A C_{1}, A C_{2}, A C_{3}$, and $A C_{4}, C F$ s were denoted as $A C_{1}$, while $A C F$ s and $M C C F$ s were expressed as $A C F_{2}$ and $A C F_{3}$, respectively. Five composite materials were prepared using the $\mathrm{AC}$ and $\mathrm{ACF}$ in different ratios, and experiments were conducted to assess their acetaldehyde adsorption efficiency under dry and wet conditions. The results showed that the acetaldehyde adsorption efficiency of an impregnated $\mathrm{AC}_{4}$ was higher $(95.9 \%)$ than that of both non-impregnated $\mathrm{AC}_{1}$ and $\mathrm{AC}_{3}$ and an impregnated $\mathrm{AC}_{2}$ after 1 min of operation. $\mathrm{ACF}_{2}$ showed a higher acetaldehyde adsorption efficiency $(50.9 \%)$ as compared to $\mathrm{ACF}_{1}$ and $\mathrm{ACF}_{3}$ because of its larger surface area and selective absorption capability after $1 \mathrm{~min}$ of operation. A composite material comprising $6.3 \mathrm{~g}$ of $\mathrm{AC}_{4}$ and $1 \mathrm{~g}$ of $\mathrm{ACF}_{2}$ showed the highest adsorption efficiency of $97.9 \%$ under dry conditions. However, this adsorption efficiency significantly decreased under wet conditions.
\end{abstract}

Keywords: Acetaldehyde, Activated carbon, Activated carbon fiber, Adsorption

\section{Introduction}

Carbon compounds, excluding carbon dioxide, carbon monoxide, carbonic acid, ammonium carbonate, and metallic carbides or carbonates that are involved in atmospheric photochemical reactions are known as volatile organic compounds (VOCs) [1]. They generally have a high vapor pressure and low boiling point and exhibit strong reactivity, primarily in photochemical reactions [2]. They have received considerable attention because of their toxic and carcinogenic nature [3, 4]. An increase in VOC emissions leads to air pollution, which has become a major global issue due to its damaging impact on the environment and human health [5-7]. VOCs affect the environment not only by intensifying global warming and photochemical smog, but also by directly or indirectly causing problems for human health. Long-time exposure to a concentration of VOCs ( $<100$ ppmv) can cause many health issues, such as liver and kidney failure, cancer, and respiratory ailments; moreover, long-term exposure even with standard concentration limits can damage various organs [8-10]. Therefore, it is important to remove VOCs, especially from indoor environments such as in buildings

This is an Open Access article distributed under the term of the Creative Commons Attribution Non-Commercial License (http://creativecommons.org/licenses/by-nc/3.0/) which permits unrestricted non-commercial use, distribution, and reproduction in any medium, provided the original work is properly cited.

Copyright (C) 2022 Korean Society of Environmental Engineers and vehicles, to minimize their impacts on the human body [11] Among VOCs, acetaldehyde, the most abundant aldehyde in the atmosphere, can cause many serious health-related problems, such as respiratory paralysis, convulsions, and corneal injury [12, 13]. It is a typical VOC to indoor air and has been reported in most buildings with concentrations of approximately $93 \mathrm{ppb}$ [14]. It can also reach extremely high concentrations of up to $720 \mathrm{ppb}$ [15]. It is an odorous compound at a low concentration of 0.09 $\mathrm{mg} / \mathrm{m}^{3}$, and its sources in buildings primarily include paints, glues, fuel additives, and deodorants [16, 17].

Numerous studies have investigated the efficiency of different adsorbents such as activated carbon (AC), silica, polymers, and zeolites to remove VOCs [18]. AC is commonly used as an adsorbent because of its capacity to adsorb substances from both gaseous and liquid phases [19-21]. The high applicability of AC is based on its physicochemical characteristics such as rapid adsorption, high porosity, and thermal stability. These properties make it suitable for the adsorption of gaseous pollutants from the air through physisorption [22]. Additionally, the chemical surface of AC-based adsorbents can be modified by adding heteroatoms, such as nitrogen

Received September 29, 2020 Accepted March 20, 2021

${ }^{\dagger}$ Corresponding author

E-mail: wtlee@kumoh.ac.kr

Tel: +8254478 7636 Fax: +8254478 7859

ORCID: 0000-0001-9660-4455 
or sulfur and oxygen that provide interaction support for adsorption [23]. AC can be used to remove odoriferous compounds from the air and has been successfully used in various purification processes. AC-based filters are currently used in cars to adsorb various environmentally hazardous substances, such as gasoline vapors; they have also been installed in cleanrooms to remove odors [24]. The odor-causing substance can react chemically with the surface of the adsorbent to form a nonvolatile and non-odoriferous compound, or it can simply be adsorbed. An efficient adsorbent is capable of removing all odoriferous compounds present in its surroundings, even in trace amounts, and retaining those compounds under near-saturation conditions [25]. Adsorption of VOCs including toluene and butane on ACs was studied concerning temperature and humidity effects [25, 26]. The same group of researchers explored ACs adsorption capacity for nitrogen dioxide at different gas concentrations, temperatures, and relative humidity [27].

Acetaldehyde is an abundant VOC in the atmosphere that can cause many serious health-related issues therefore its removal from the air is important. The adsorption capacity of AC for acetaldehyde removal has been reported to not be promising, as discussed in the literature $[24,28]$. It was reported that the acetaldehyde adsorption capacity of impregnants $\mathrm{AC}$ is affected by the steric structure and acidity [29]. A recent study showed that cellulose-based AC fibers (CACFs) can be used as a potential adsorbent for the adsorption of acetaldehyde from the air [30]. However, no studies in the literature have investigated acetaldehyde adsorption by activated carbon and carbon fiber adsorbents. Additionally, no comparative study for activated carbon and carbon fiber-based adsorbents has been found in the literature as per author's knowledge. Therefore, the adsorption of acetaldehyde onto selected carbon-based adsorbents, including AC, carbon fibers (CFs), activated carbon fibers (ACFs), and metal-coated carbon fibers (MCCFs) was studied to determine the best adsorbent among them. Moreover, five composite adsorbents were prepared using different amounts of efficient adsorbents. They were then tested to identify the best combination under dry and wet conditions in order to evaluate the influence of humidity on their acetaldehyde adsorption efficiency.

\section{Materials and Methods}

\subsection{Materials}

In this study, the ability of selected carbon-based adsorbents to remove acetaldehyde from the air was investigated. The adsorbents studied included AC, CFs, ACFs, and MCCFs. AC samples were classified as $\mathrm{AC}_{1}$ (non-impregnated) and $\mathrm{AC}_{2}$ (impregnated), provided by one supplier, and $\mathrm{AC}_{3}$ (non-impregnated) and $\mathrm{AC}_{4}$ (impregnated), supplied by another manufacturer. In addition, CFs were categorized as $\mathrm{ACF}_{1}(\mathrm{CFs}), \mathrm{ACF}_{2}$ (ACFs), and $\mathrm{ACF}_{3}$ (MCCFs). The characteristics of the selected carbon-based adsorbents and details of their suppliers are presented in Table 1.

\subsection{Experimental Setup}

The adsorption test was performed using a lab-scale column setup consisting of $300 \mathrm{~mm}$ steel columns placed in series with an inner diameter of $5 \mathrm{~mm}$, as shown in Fig. 1. The setup was positioned in a temperature-controlled environment at $20^{\circ} \mathrm{C}$, and the injection

Table 1. Characteristics of Selected Carbon-Based Adsorbents

\begin{tabular}{lccccc} 
No. & Adsorbent & Appearance & BET $^{*}$ & PSA $^{* *}$ & Supplier $^{*}$ \\
1 & $\mathrm{AC}_{1}$ & Powder & $1,338 \pm 10.8$ & 939.33 & Jayeon science, Korea \\
2 & $\mathrm{AC}_{2}$ & Powder & $1,377 \pm 10.7$ & 918.32 & Jayeon science, Korea \\
3 & $\mathrm{AC}_{3}$ & Powder & $992 \pm 8.4$ & 596.69 & Diotech, Korea \\
4 & $\mathrm{AC}_{4}$ & Powder & $1,487 \pm 5.8$ & 576.24 & Diotech, Korea - \\
5 & $\mathrm{ACF}_{1}$ & Fibrous & $22 \pm 0.3$ & - & Bullson materials, Korea \\
6 & $\mathrm{ACF}_{2}$ & Fibrous & $1,281 \pm 16.9$ & - & Bullson materials, Korea \\
7 & $\mathrm{ACF}_{3}$ & Silver coated CF & $1,187 \pm 16.2$ & - & Bullson materials, Korea \\
\hline
\end{tabular}

AC; Activated carbon, ACF1; Carbon fiber, ACF2; Activated carbon fiber, ACF3; Metal coated carbon fiber, * Brunauer Emmett Teller surface area; ${ }^{*}$ Particle size analysis (d50);

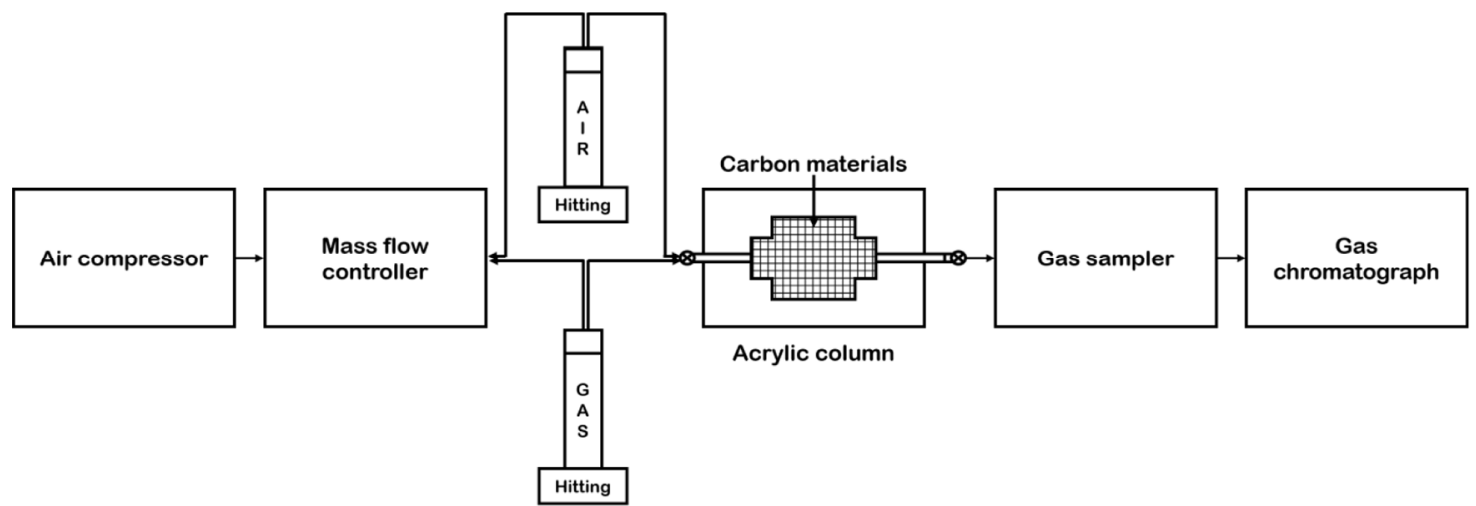

Fig. 1. Schematic diagram of the experimental setup. 
of feed gas into the column was controlled by a regulator at 12 L/min. Under general experiments and dry conditions, the humidity was maintained at $40-50 \%$, while under wet conditions, the humidity was maintained at $90 \%$. Adsorption experiments were performed for $90 \mathrm{~min}$ and samples were collected and analyzed at 0, 1, 5, $10,15,20,25,30,60$, and $90 \mathrm{~min}$ after injection.

\subsection{Surface Characterization of Adsorbents}

To assess the impact of the treatments, the changes in the surface morphology of the modified carbon samples were analyzed using scanning electron microscopy (SEM). In this experiment, double-sided silver tapes of $1 \mathrm{~cm}$ diameter aluminum stubs with 10 $\mu \mathrm{m}$ carbon layers were used for mounting the samples. The samples were then analyzed using a JSM-6380 scanning electron micro-spectrometer (JEOL Ltd., Japan) operated at 5-20 keV. The morphology of the AC samples dried overnight at approximately $105^{\circ} \mathrm{C}$ in a vacuum with a 3-kV accelerating voltage was characterized before SEM analysis. Energy-dispersive spectroscopy (EDS) was used to determine the surface elemental composition. The adsorption and desorption of nitrogen onto carbon materials were measured at $77 \mathrm{~K}$ using a porosimeter system (3FLEX, Micromeritics Instrument Corp.) to determine the Brunauer-Emmett-Teller (BET) surface area, pore size distribution, and total pore volume. The samples were degassed under vacuum conditions at a temperature of $350^{\circ} \mathrm{C}$ and pressure of $10^{-5}$ Torr for $10 \mathrm{~h}$ before measurement, and approximately $0.15 \mathrm{~g}$ of the samples were used during the adsorption experiments. The BET surface area, pore size distribution, total pore volume, and micropore volume were evaluated based on the nitrogen adsorption profile, and the specific surface area at relative pressures in the range of 0.05-0.30 was determined using the BET method.
The total pore volume was estimated directly from the held volume of nitrogen measured at the highest relative pressure (0.99), and the micropore volume was calculated using the DubininRadushkevich (DR) equation. The quantitative analysis of elements was conducted by inductively coupled plasma optical emission spectroscopy (ICP-OES) analyses using a 720-ES spectrometer manufactured by Varian. The instrument used a specific volume of $2.5 \mathrm{~mL}$ (extracted from the diluted solutions) for analysis, and the mean values of element concentrations were reported in ppm.

\section{Results and Discussion}

\subsection{Structural and Elemental Composition of Selected Carbon-Based Adsorbents}

The surface textures of the selected carbon-based adsorbents were characterized using SEM at various magnifications, as presented in Fig. 2. The surface textures of AC were detected as regular and smooth with a lower degree of roughness and waviness are known as modulations, while the surface texture of ACF was found to be rough because of the greater number of modulations [30]. These adsorbents were subjected to adsorption at various magnifications of X1000 and X5000. As mentioned in the previous section, the microstructure and elemental composition of $\mathrm{AC}_{1}, \mathrm{AC}_{2}, \mathrm{AC}_{3}$, $\mathrm{AC}_{4}, \mathrm{ACF}_{1}, \mathrm{ACF}_{2}$, and $\mathrm{ACF}_{3}$ were evaluated using SEM-EDS. Carbon $(\mathrm{C})$, oxygen $(\mathrm{O})$, potassium $(\mathrm{K})$, silicon $(\mathrm{Si})$, chloride $(\mathrm{Cl})$, sulfur $(\mathrm{S})$, phosphorus $(\mathrm{P})$, and sodium $(\mathrm{Na})$ were detected by EDS in all the samples. The percentage of elements (wt \%) present in $\mathrm{AC}_{1}, \mathrm{AC}_{2}, \mathrm{AC}_{3}$, and $\mathrm{AC}_{4}$ was investigated and determined as
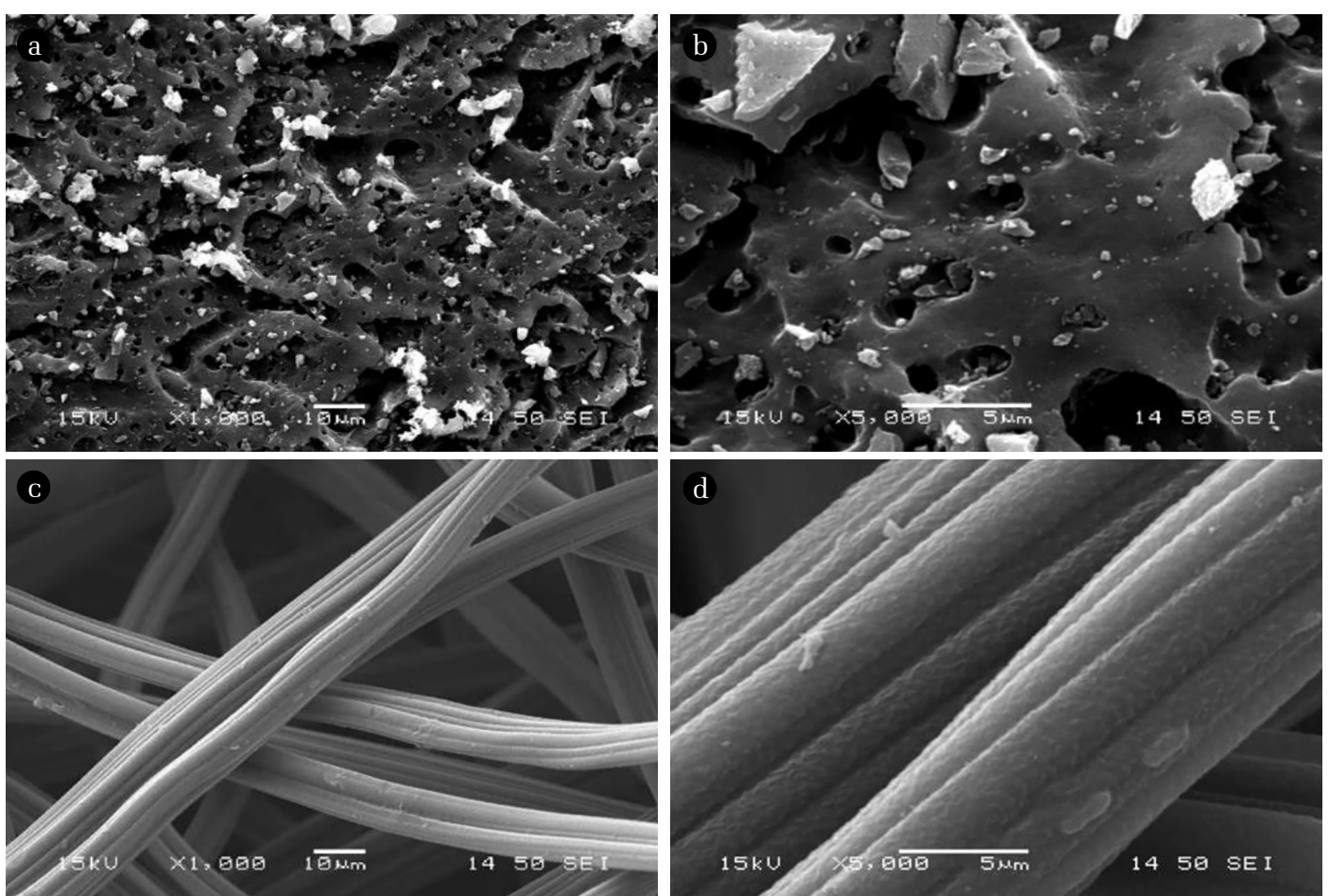

Fig. 2. SEM images of (a) $A_{4} X 1000$, (b) $A_{4} X 5000$, (c) $A_{4} F_{2} X 1000$, (d) $A_{C F} X_{2} 5000$. 
$\mathrm{C}(63.77 \%)>\mathrm{O}(22.33 \%)>\mathrm{K}(12.90 \%), \mathrm{C}(81.41 \%)>\mathrm{O}(12.09 \%)$ $>\mathrm{K}(6.41 \%)>\mathrm{Si}(0.09 \%), \mathrm{C}(94.08 \%)>\mathrm{O}(5.24 \%)>\mathrm{K}(0.68 \%)$, and $\mathrm{C}(89.46 \%)>\mathrm{O}(8.72 \%)>\mathrm{S}(1.75 \%)>\mathrm{Cl}(0.07 \%)$, respectively. Moreover, the percentage of elements (wt \%) present in $\mathrm{ACF}_{1}$, $\mathrm{ACF}_{2}$, and $\mathrm{ACF}_{3}$ was determined as $\mathrm{C}(90.26 \%)>\mathrm{O}(9.74 \%), \mathrm{C}$ $(80.75 \%)>\mathrm{O}(16.40 \%)>\mathrm{P}(2.16 \%)>\mathrm{Na}(0.69 \%)$, and C $(86.46 \%)$ $>\mathrm{O}(13.38 \%)>\mathrm{Na}(0.16 \%)$, respectively. The elemental analysis classified elements as micro, macro, and trace based on their concentrations. Eleven of the 32 elements detected in the AC-based adsorbents and their quantitative analysis was conducted using ICP-OES are presented in Table 2. Analytical studies indicated that the selected adsorbents were rich in $\mathrm{K}, \mathrm{Na}$, and $\mathrm{Ca}$, followed by $\mathrm{Mg}$ and $\mathrm{Fe}$. In the case of $\mathrm{AC}_{1}, \mathrm{~K}$ showed the highest concentration $(18,641 \mu \mathrm{g} / \mathrm{g})$, whereas both $\mathrm{B}$ and $\mathrm{Zn}$ were found to have the lowest concentrations (non-detected). In the case of $\mathrm{AC}_{2}, \mathrm{~K}$ showed the highest concentration $(16,148 \mu \mathrm{g} / \mathrm{g})$, whereas $\mathrm{Cr}, \mathrm{Si}$, and $\mathrm{Zn}$ were found to have the lowest concentrations (non-detected). In the case of $\mathrm{AC}_{3}, \mathrm{~K}$ also showed the highest concentration (4,716 $\mu \mathrm{g} / \mathrm{g}$ ), whereas $\mathrm{Zn}$ was found to have the lowest concentration (non-detected). In the case of $\mathrm{AC}_{4}, \mathrm{Fe}$ showed the highest concentration (76 $\mu \mathrm{g} / \mathrm{g})$, and $\mathrm{B}, \mathrm{Ca}, \mathrm{Cr}, \mathrm{Mg}, \mathrm{Na}, \mathrm{S}, \mathrm{Si}$, and $\mathrm{Zn}$ were found to have the lowest concentrations (non-detected). SEM images clearly

Table 2. Elemental Analysis of Selected Activated Carbons (ACs)

\begin{tabular}{lcccc}
\hline \multirow{2}{*}{ Elements } & \multicolumn{4}{c}{ Detected concentration (mg/Kg) } \\
\cline { 2 - 5 } & $\mathbf{A C}_{\mathbf{1}}$ & $\mathbf{A C}_{\mathbf{2}}$ & $\mathbf{A C}_{\mathbf{3}}$ & $\mathbf{A C}_{\mathbf{4}}$ \\
$\mathrm{Al}$ & 154 & 74 & 247 & 43 \\
$\mathrm{~B}$ & - & 173 & 54 & - \\
$\mathrm{Ca}$ & 507 & 473 & 346 & - \\
$\mathrm{Cr}$ & 129 & - & 114 & - \\
$\mathrm{Fe}$ & 210 & 155 & 181 & 76 \\
$\mathrm{~K}$ & 18,641 & 16,148 & 4,716 & 67 \\
$\mathrm{Mg}$ & 278 & 273 & 226 & - \\
$\mathrm{Na}$ & 531 & 273 & 463 & - \\
$\mathrm{P}$ & 252 & 244 & 231 & - \\
$\mathrm{Si}$ & 69 & - & 259 & - \\
$\mathrm{Zn}$ & - & - & - & -
\end{tabular}

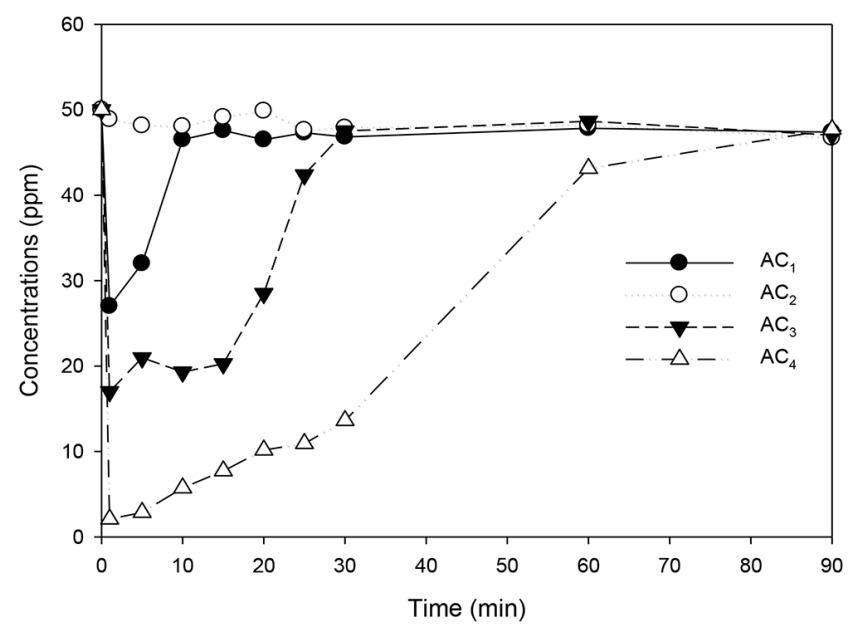

Fig. 3. Acetaldehyde adsorption efficiency of ACs. explained the surface morphology of adsorbents while qualitative and quantitative elemental analysis provided insight on composing elements of the adsorbents. It can help to understand the adsorption phenomena of acetaldehyde onto selected adsorbents and can assist in the preparation of the best adsorbent for future studies.

\subsection{Acetaldehyde Adsorption by the Selected Carbon-Based Adsorbents}

The acetaldehyde adsorption efficiencies of the targeted AC samples, including $\mathrm{AC}_{1}, \mathrm{AC}_{2}, \mathrm{AC}_{3}$, and $\mathrm{AC}_{4}$, are presented in Fig. 3. The AC samples were impregnated with an amine at various injection times: $0,1,5,10,15,20,25,30,60$, and $90 \mathrm{~min}$. The initial concentration of the AC samples was approximately 49-50 ppm, and the effluent concentration level was reduced to $47 \mathrm{ppm}$. The adsorption efficiencies of the AC samples were determined by measuring the concentrations of acetaldehyde in the outflows from the acrylic column. Overall, the adsorption efficiencies of most AC samples were the highest after 1 min (initial time) of circulating in the acrylic columns. The acetaldehyde adsorption efficiency of $\mathrm{AC}_{1}$ was found to be $46.0 \%$ after $1 \mathrm{~min}$ of operation, whereas $90 \mathrm{~min}$ later, it reduced to $5.30 \%$ under constant conditions. It was observed that $\mathrm{AC}_{2}$ did not perform well in removing acetaldehyde under the same time intervals, and its highest adsorption efficiency was only $6.60 \%$. The acetaldehyde adsorption efficiency of $\mathrm{AC}_{3}$ was higher than that of both $\mathrm{AC}_{1}$ and $\mathrm{AC}_{2}$; its efficiency was $66.0 \%$ after $1 \mathrm{~min}$ and $6.0 \%$ after $90 \mathrm{~min}$ of operation. $\mathrm{AC}_{4}$ showed the highest acetaldehyde adsorption efficiency $(95.9 \%)$ after $1 \mathrm{~min}$ of operation and gradually decreased over time up to $30 \mathrm{~min}$; however, a sharp drop was observed following this. Based on these column experiments, the acetaldehyde adsorption efficiency of $\mathrm{AC}_{4}$ was higher than those of $\mathrm{AC}_{1}$ and $\mathrm{AC}_{3}$, while it outperformed $\mathrm{AC}_{2}$. Therefore, $\mathrm{AC}_{4}$, which is an impregnated $\mathrm{AC}$, can be considered a promising adsorbent for the adsorption of acetaldehyde from the air. These results are supported by those of a previous study in which the adsorption capacity of impregnated AC using various impregnants was explored based on their steric structure and acidity for acetaldehyde adsorption [29]. Therefore, the highest adsorption of acetaldehyde by $\mathrm{AC}_{4}$ might be achieved because of lesser benzene ring presence in the impregnated amine that hinders the condensation of acetaldehyde. Moreover, $\mathrm{AC}_{4}$ has a higher surface area and lower particle size analysis as presented in Table 1 that might be another factor for accomplishing the highest adsorption.

Fig. 4 shows the adsorption efficiencies of acetaldehyde from the air by ACFs such as $\mathrm{ACF}_{1}, \mathrm{ACF}_{2}$, and $\mathrm{ACF}_{3}$. These are newly proposed fibrous carbonaceous materials that can be prepared through the carbonization and activation of organic fibers at a temperature of $700-1,000^{\circ} \mathrm{C}$ in the presence of carbon dioxide or steam [31]. The injection interval times were similar to those used in the AC experiments: $0,1,5,10,15,20,25,30,60$, and 90 min. The initial concentration of ACFs was approximately 54-55 ppm, and the effluent concentration level was reduced to $54 \mathrm{ppm}$. Acetaldehyde was rapidly removed and adsorbed by ACFs, and the reaction speed dropped quickly after approximately $1 \mathrm{~min}$. The results presented by $\mathrm{ACF}_{1}$ indicated that its adsorption efficiency was lowest throughout the aforementioned experimental period, 


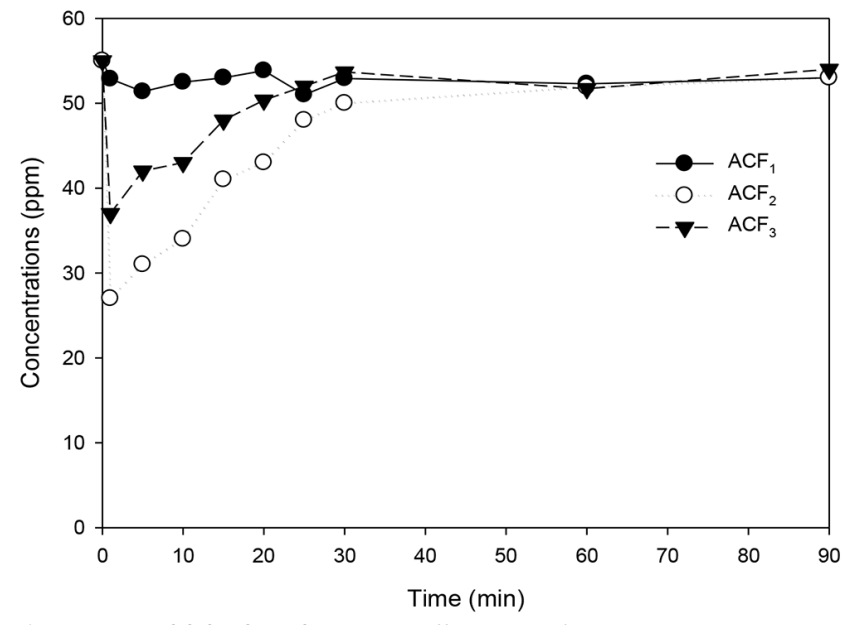

Fig. 4. Acetaldehyde adsorption efficiency of ACFs.

while $\mathrm{ACF}_{2}$ showed a high adsorption efficiency of up to $50.9 \%$ after 1 min of operation. The acetaldehyde adsorption efficiency of $\mathrm{ACF}_{3}$ was better than that of $\mathrm{ACF}_{1}$ but poor compared to $\mathrm{ACF}_{2}$. Therefore, the results demonstrated that $\mathrm{ACF}_{2}$ outperformed $\mathrm{ACF}_{1}$ and showed comparatively higher adsorption efficiency than $\mathrm{ACF}_{3}$. Similar results were derived in a previous study on cellulose-based ACFs modified by an amine functional group for the adsorption of acetaldehyde under $40 \%$ humidity conditions [32]. At start acetaldehyde adsorbed physically onto the active sites with oxygen and nitrogen of adsorbent that creates a bonding with acetaldehyde molecule quickly.

\subsection{Acetaldehyde Adsorption by Composite Adsorbents un- der Dry and Wet Conditions}

In the previous sections, we noted that $\mathrm{AC}_{4}$ and $\mathrm{ACF}_{2}$ were the best adsorbents in terms of their efficiency to remove acetaldehyde from air compared to other selected adsorbents. For further studies, composite adsorbents were prepared by mixing different amounts of $\mathrm{AC}_{4}$ and $\mathrm{ACF}_{2}$. The composites were tested to explore the change in adsorption capacity of mixed materials and also analyzed the effect of the mixing ratio. Five composites were prepared using a defined mixing ratio as described in Table S1. This mixing ratio was decided based-on the maximum filling capacity of the column, it was not possible to place more than $2 \mathrm{~g}$ of $\mathrm{ACF}_{2}$ therefore, we tried different $1 \pm 0.5 \mathrm{~g}$ of ACF with different combinations of $\mathrm{AC}_{4}$. The results presented in Fig. 5 and Fig. 6 show the acetaldehyde adsorption efficiencies of the prepared composite adsorbents under dry and wet conditions. In addition, experiments were conducted to study the effect of humidity on the composite materials under dry and wet conditions. Under dry conditions, the temperature was $20^{\circ} \mathrm{C}$ and the humidity was maintained at $50 \%$, while under wet conditions, the humidity was maintained at $90 \%$ at the same temperature. The acetaldehyde concentration of composite adsorbents 1-5 in the outlets decreased gradually during $90 \mathrm{~min}$ of operation.

Under dry conditions, the acetaldehyde adsorption efficiency of the first composite was found to be the lowest at $7.5 \%$ after 1 min of operation under constant conditions. The acetaldehyde adsorption efficiency of the second composite was the highest (97.9\%) after $1 \mathrm{~min}$ of operation; it then dropped slightly and sharply decreased later, as shown in Fig. 5. The highest adsorption efficiency of the third composite was $86.5 \%$, while it was $91.5 \%$ and $86.6 \%$ for the fourth and fifth composites, respectively, after $1 \mathrm{~min}$ of operation. Therefore, based on the column experiments, the second composite (6.3 $\mathrm{g}$ of $\mathrm{AC}_{4}$ and $1 \mathrm{~g}$ of $\mathrm{ACF}_{2}$ ) showed higher adsorption efficiencies of acetaldehyde as compared to other composite adsorbents. Moreover, under wet conditions, the acetaldehyde adsorption efficiency of the first composite varied between 1.9 and $3.7 \%$, while for the second composite, it ranged from $1.6 \%$ to $8.0 \%$. For the third composite, the adsorption efficiency was between $0.1 \%$ and $8.4 \%$, whereas for the fourth and fifth composites ranged from 1.3 to $14.8 \%$ and 0.1 . $22.6 \%$, respectively, during similar time intervals, as shown in Fig. 6. The results indicated that the performance of the composite adsorbents in terms of acetaldehyde adsorption from the air was poor under wet conditions. The

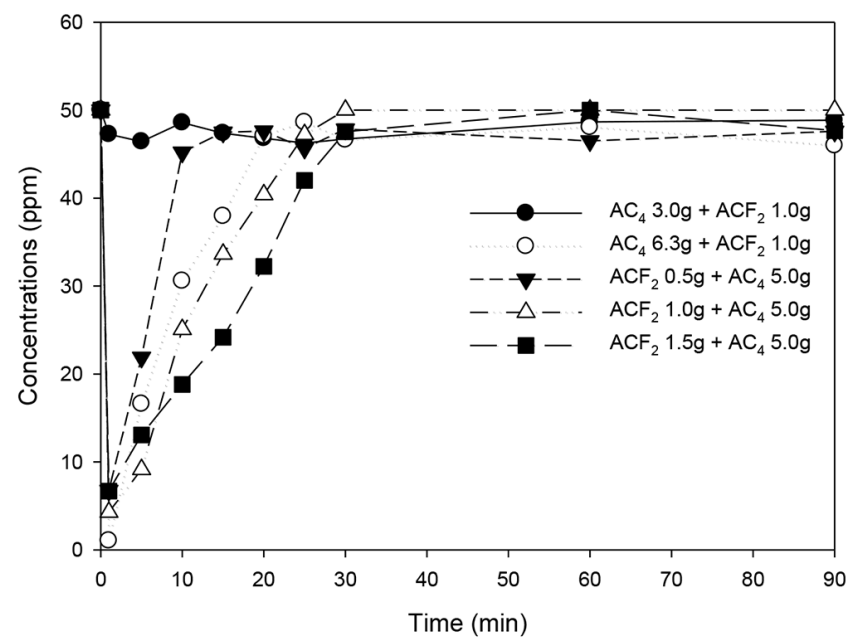

Fig. 5. Acetaldehyde adsorption efficiency of composites under dry conditions.

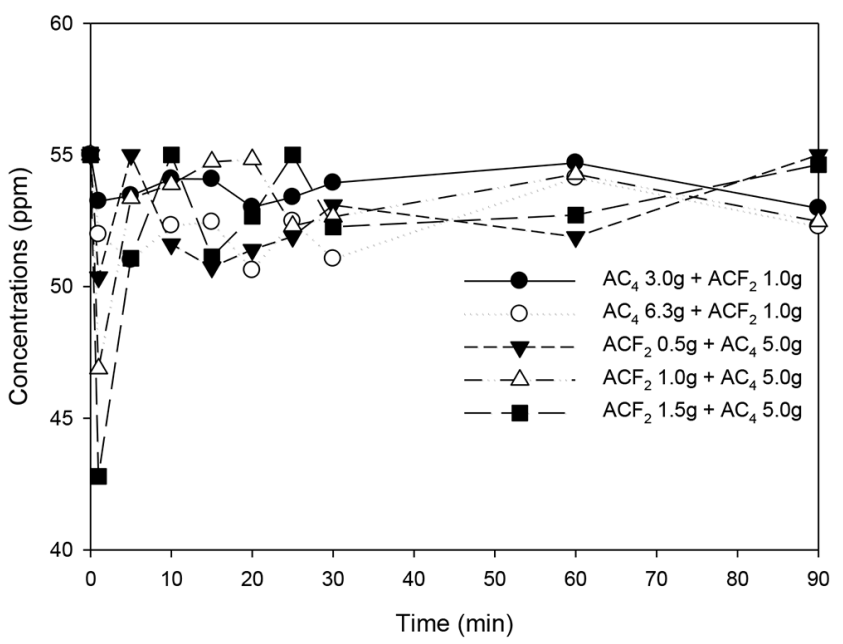

Fig. 6. Acetaldehyde adsorption efficiency of composites under wet conditions. 
adsorption efficiencies of the composite materials under wet conditions were lower than those under dry conditions, as mentioned in previous studies [32-34]. Generally, in wet conditions water vapors occupy the active sites of adsorbent and resulted in lower adsorption of acetaldehyde. In case of high relative humidity more water molecule adsorbs at the active sites of the adsorbent that ultimately decrease their efficiency to remove acetaldehyde. The acetaldehyde is trapped into moisture under wet conditions due to its hydrophilic nature and penetrates the micropores but overall efficiency is dropped. Therefore, wet conditions are not favorable for the adsorption of acetaldehyde from the air using selected carbon-based adsorbents.

\section{Conclusions}

The acetaldehyde adsorption efficiency of activated carbon and carbon fiber-based adsorbents such as AC, CFs, ACFs, and MCCFs was investigated in this study. Acetaldehyde adsorption efficiencies of most carbon materials decreased as the traveling time in the column increased. With AC, the acetaldehyde adsorption efficiency of $\mathrm{AC}_{4}$ (impregnated $\mathrm{AC}$ ) was higher (95.9\%) than other ACs after 1 min of operation. This may be becuase of the high BET surface area that provides more sites for acetaldehyde adsorption. For ACFs, the acetaldehyde adsorption efficiency of $\mathrm{ACF}_{2}$ was higher $(50.9 \%)$ than other ACFs after 1 min of operation. $\mathrm{ACF}_{2}$ has a systematic open macrostructure that results in a low-pressure drop and allows fast adsorption with no diffusion hindrance. Moreover, experiments were conducted to explore the effect of humidity on the composite adsorbents under dry and wet conditions. The composite adsorbent that comprised $6.3 \mathrm{~g}$ of $\mathrm{AC}_{4}$ and $1 \mathrm{~g}$ of $\mathrm{ACF}_{2}$ showed the highest adsorption efficiency compared with other composites under dry conditions. However, under wet conditions, all the adsorbents were inefficient in removing acetaldehyde from the air.

\section{Acknowledgments}

This work was supported by the Technology Innovation Program (10076393), funded by the Ministry of Trade, Industry \& Energy (MOTIE, Korea)

\section{Author Contributions}

S.P. (Postdoc researcher) performed the experimental work and prepared a draft of the manuscript; M.Y. (Postdoc researcher) performed data analysis, compiled the results, and rewrote the manuscript; S.L. (Research fellow) performed data analysis and revised the manuscript; and W.L. (Professor) funding and revision of the manuscript.

\section{References}

1. United States Environmental Protection Agency. Indoor Air Quality (IAQ), Tehnical Overview of Volatile Organic
Compounds, 2017.

2. Salthammer T. Very volatile organic compounds: an understudied class of indoor air pollutants. Indoor Air. 2016;26:25-38.

3. Zhang X, Li L, Guo Y, Liu D, You T. Amorphous flower-like molybdenum-sulfide-nitrogen-doped-carbon-nanofiber film for use in the hydrogen-evolution reaction. J. Colloid. Interface Sci. 2016;472:69-75.

4. Zhang X, Gao B, Creamer AE, Cao C, Li Y. Adsorption of VOCs onto engineered carbon materials: A review. J. Hazard. Mater. 2017;338:102-123.

5. Kim M, Kim S, Lim C, Seo B. Adsorption of acetaldehyde at room temperature in a continuous system using silica synthesized by the sol-gel method. Korean J. Chem. Eng. 2017;34: 2773-2779.

6. Rangkooy HA, Pour MN, Dehaghi BF. Efficiency evaluation of the photocatalytic degradation of zinc oxide nanoparticles immobilized on modified zeolites in the removal of styrene vapor from air. Korean J. Chem. Eng. 2017;34:3142-3149.

7. Jeon JW, Lee DH, Won YS, Lee MG. Characteristics of photocatalytic decomposition of individual and binary mixture vapors of some VOCs by a cylindrical UV reactor with helically installed $\mathrm{TiO}_{2}$-coated perforated planes. Korean J. Chem. Eng. 2018;35: 744-749.

8. Huang ZH, Kang F, Zheng YP, Yang JB, Liang KM. Adsorption of trace polar methy-ethyl-ketone and non-polar benzene vapors on viscose rayon-based activated carbon fibers. Carbon N. Y. 2002;40:1363-1367.

9. Xie H, Du Q, Li H, Zhou G, Chen S, Jiao Z, Ren J. Catalytic combustion of volatile aromatic compounds over $\mathrm{CuO}-\mathrm{CeO}_{2}$ catalyst. Korean J. Chem. Eng. 2017;34:1944-1951.

10. Yi Y, Li C, Zhao L, et al. The synthetic evaluation of CuO-MnO $\mathrm{x}$-modified pinecone biochar for simultaneous removal formaldehyde and elemental mercury from simulated flue gas. Environ. Sci. Pollut. Res. 2018;25:4761-4775.

11. Aivalioti M, Vamvasakis I, Gidarakos E. BTEX and MTBE adsorption onto raw and thermally modified diatomite. J. Hazard. Mater. 2010;178:136-143.

12. Kang BS, Hong Y, Lee H, et al. Removal of food waste odor using nanoporous carbon adsorbents. J. Nanosci. Nanotechnol. 2018;18:1492-1494.

13. Sakugawa H, Kaplan IR, Shepard LS. Measurements of $\mathrm{H}_{2} \mathrm{O}_{2}$, aldehydes and organic acids in Los Angeles rainwater: their sources and deposition rates. Atmos. Environ. Part B. Urban Atmos. 1993;27:203-219.

14. Marchand C, Bulliot B, Le Calvé S, Mirabel P. Aldehyde measurements in indoor environments in Strasbourg (France). Atmos. Environ. 2006;40:1336-1345.

15. Liu Q, Liu Y, Zhang M. Personal exposure and source characteristics of carbonyl compounds and BTEXs within homes in Beijing, China. Build. Environ. 2013;61:210-216.

16. Atkinson R. Atmospheric chemistry of VOCs and NOx. Atmos. Environ. 2000;34:2063-2101.

17. Golden R. Identifying an indoor air exposure limit for formaldehyde considering both irritation and cancer hazards. Crit. Rev. Toxicol. 2011;41:672-721.

18. Kim JM, Kim JH, Lee CY, Jerng DW, Ahn HS. Toluene and acetaldehyde removal from air on to graphene-based adsorbents 
with microsized pores. J. Hazard. Mater. 2018;344:458-465.

19. Daifullah AAM, Girgis BS, Gad HMH. Utilization of agro-residues (rice husk) in small waste water treatment plans. Mater. Lett. 2003;57:1723-1731.

20. Dizbay-Onat M, Floyd E, Vaidya UK, Lungu CT. Applicability of industrial sisal fiber waste derived activated carbon for the adsorption of volatile organic compounds (VOCs). Fibers Polym. 2018;19:805-811.

21. Wong S, Ngadi N, Inuwa I.M, Hassan O. Recent advances in applications of activated carbon from biowaste for wastewater treatment: a short review. J. Clean. Prod. 2018;175:361-375.

22. Budinova T, Ekinci E, Yardim F, et al. Characterization and application of activated carbon produced by $\mathrm{H}_{3} \mathrm{PO}_{4}$ and water vapor activation. Fuel Process. Technol. 2006;87:899-905.

23. Guedidi H, Reinert L, Soneda Y, Bellakhal N, Duclaux L. Adsorption of ibuprofen from aqueous solution on chemically surface-modified activated carbon cloths. Arab. J. Chem. 2017;10:3584-3594.

24. El-Sayed Y, Bandosz T.J. Acetaldehyde adsorption on nitrogen-containing activated carbons. Langmuir 2002;18:3213-3218.

25. Görgülü A, Yağli H, Koç Y, Koç A, Baltacioğlu E. Activated carbon adsorption behaviour of toluene at various temperatures and relative humidity. Environ. Prot. Eng. 2019;45:111-126.

26. Görgülü A, Yağlı H, Koç H, Koç A, Öztürk NA, Köse Ö. Experimental study of butane adsorption on coconut based activated carbon for different gas concentrations, temperatures and relative humidities. Environ. Technol. 2019;16:1-10.
27. Görgülü A, Koç Y, Yağlı H, Koç A. Adsorption of nitrogen dioxide $\left(\mathrm{NO}_{2}\right)$ for different gas concentrations, temperatures and relative humidities by using activated carbon filter: An experimental study. Int. J. Adv. Eng. Res. Sci. 2018;5:1-7.

28. Hayashi T, Kumita M, Otani Y. Removal of acetaldehyde vapor with impregnated activated Carbons: Effects of steric structure on impregnant and acidity. Environ. Sci. Technol. 2005;39: 5436-5441.

29. Ryu D-Y, Nakabayashi K, Shimohara T, et al. Behaviors of Cellulose-Based Activated Carbon Fiber for Acetaldehyde Adsorption at Low Concentration. Appl. Sci. 2020;10:25.

30. Feng W, Kwon S, Borguet E, Vidic R. Adsorption of hydrogen sulfide onto activated carbon fibers: effect of pore structure and surface chemistry. Environ. Sci. Technol. 2005;39:9744-9749.

31. Lee T, Ooi C-H, Othman R, Yeoh F-Y, Activated carbon fiber-the hybrid of carbon fiber and activated carbon. Rev. Adv. Mater. Sci. 2014;36:118-136.

32. Pak S-H, Jeon Y-W. Effect of vacuum regeneration of activated carbon on volatile organic compound adsorption. Environ. Eng. Res. 2016;22:169-174.

33. Han SW, Lee JH, Kim JS, Oh SH, Park YK, Kim H. Gaseous by-products from the TiO 2 Photocatalytic Oxidation of Benzene. Environ. Eng. Res. 2008;13:14-18.

34. Lamorena RB. Ultra-fine particles and gaseous volatile organic compound exposures from the reaction of ozone and car-air freshener during metropolis travel. Environ. Eng. Res. 2007;12:72-80. 